\title{
BMJ Open Randomised placebo-controlled study of the effect of paracetamol on asthma severity in adults
}

Sally J loannides, ${ }^{1,2,3}$ Mathew Williams, ${ }^{1}$ Sarah Jefferies, ${ }^{1,2}$ Kyle Perrin, ${ }^{1,2}$ Mark Weatherall, ${ }^{2,3}$ Robert Siebers, ${ }^{3}$ Julian Crane ${ }^{3}$ Mitesh Patel, ${ }^{1,2}$ Justin Travers, ${ }^{1}$ Philippa Shirtcliffe, ${ }^{1,2}$ Richard Beasley ${ }^{1,2}$

To cite: Ioannides SJ, Williams $\mathrm{M}$, Jefferies $\mathrm{S}$, et al. Randomised placebocontrolled study of the effect of paracetamol on asthma severity in adults. BMJ Open 2014;4:e004324.

doi:10.1136/bmjopen-2013004324

- Prepublication history and additional material for this paper is available online. To view these files please visit the journal online (http://dx.doi.org/10.1136/ bmjopen-2013-004324)

Received 23 October 2013 Revised 18 December 2013 Accepted 9 January 2014

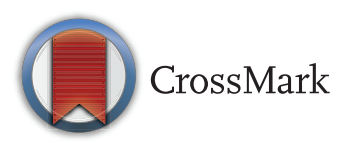

${ }^{1}$ Medical Research Institute of New Zealand, Wellington, New Zealand

${ }^{2}$ Capital \& Coast District Health Board, Wellington, New Zealand

${ }^{3}$ University of Otago Wellington, Wellington, New Zealand

Correspondence to Professor Richard Beasley; richard.beasley@mrinz.ac.nz

\section{ABSTRACT}

Objective: To investigate the effect of regular paracetamol on bronchial hyper-responsiveness (BHR) and asthma control in adult asthma.

Setting: Single research-based outpatient clinic. Participants: 94 adults with mild-to-moderate asthma received randomised treatment; 85 completed the study. Key inclusion criteria were age 18-65 years, forced expiratory volume in $1 \mathrm{~s}\left(\mathrm{FEV}_{1}\right)>70 \%$ predicted, provocation concentration of methacholine causing a $20 \%$ reduction in $\mathrm{FEV}_{1}\left(\mathrm{PC}_{20}\right)$ between 0.125 and $16 \mathrm{mg} / \mathrm{mL}$. Key exclusion criteria included an asthma exacerbation within the previous 2 months, current regular use of paracetamol, use of high-dose aspirin or non-steroidal anti-inflammatory drugs, current or past cigarette smoking $>10$ pack-years.

Interventions: In a 12-week randomised, doubleblind, placebo-controlled, parallel-group study, participants received 12 weeks of $1 \mathrm{~g}$ paracetamol twice daily or placebo twice daily.

Primary and secondary outcome measures: The primary outcome variable was BHR, measured as the $\mathrm{PC}_{20}$ at week 12. Secondary outcome variables included $\mathrm{FEV}_{1}$, fractional exhaled nitric oxide (FeNO) and asthma control questionnaire (ACQ) score.

Results: At 12 weeks, the mean (SD) logarithm base two $\mathrm{PC}_{20}$ was $1.07(2.36)$ in the control group $(\mathrm{N}=54)$ and 0.62 (2.09) in the paracetamol group ( $\mathrm{N}=31)$. After controlling for baseline $\mathrm{PC}_{20}$, the mean difference (paracetamol minus placebo) was -0.48 doubling dose worsening in BHR in the paracetamol group $(95 \% \mathrm{Cl}$ -1.28 to 0.32 ), $p=0.24$. There were no statistically significant differences (paracetamol minus placebo) in log FeNO $(0.09(95 \% \mathrm{Cl}-0.097$ to 0.27$))$, $\mathrm{FEV}_{1}(-0.07 \mathrm{~L}$ $(95 \% \mathrm{Cl}-0.15$ to 0.01$))$ or ACQ score $(-0.04(95 \% \mathrm{Cl}$ -0.27 to 0.18$)$ ).

Conclusions: There was no significant effect of paracetamol on BHR and asthma control in adults with mild-to-moderate asthma. However, the study findings are limited by low power and the upper confidence limits did not rule out clinically relevant adverse effects.

Trial Registration: Australia New Zealand Clinical Trials Registry Number: NZCTR12609000551291.

\section{Strengths and limitations of this study \\ - Randomised placebo-controlled trial. \\ - Physiological, clinical and immunological outcome measures. \\ - Powered to detect a marked effect on BHR.}

\section{INTRODUCTION}

There is a growing body of evidence to suggest that paracetamol may play an important role as a risk factor in the development of asthma, and that increasing worldwide use may have contributed to the increasing global prevalence of asthma observed over the past 40 years. ${ }^{1}{ }^{2}$ Childhood asthma risk increases in the offspring of women who consume paracetamol during pregnancy, ${ }^{3}$ and paracetamol use in the first 12 months of life is associated with an increased risk of wheezing at 3 years ${ }^{4}{ }^{5}$ and $6-7$ years. ${ }^{6}$ Cross-sectional surveys in children, ${ }^{6}$ adolescents $^{7}$ and adults $^{8-11}$ consistently demonstrate an association between current paracetamol use and asthma in populations with widely differing lifestyles, standards of living, medical practice and availability of paracetamol. However, there is also evidence that these associations may, in part, be due to confounding by indication in some,${ }^{12-14}$ but not all cohort studies in childhood. ${ }^{15}$ Cohort studies in adults have demonstrated that increasing frequency of paracetamol use is positively associated with newly diagnosed (adult-onset) asthma. ${ }^{1617}$

Evidence also indicates that paracetamol may increase the severity of asthma in those with the disease. This primarily comes from the only randomised controlled trial of the effect of paracetamol use for fever and asthma outcomes, in which asthmatic children experiencing a current febrile illness were randomised to receive either 
paracetamol or ibuprofen. ${ }^{18}$ Children who received paracetamol were more likely to require an outpatient visit for asthma compared with children in the ibuprofen group. The increased risk with paracetamol was dose dependent and related to respiratory febrile illnesses rather than other causes of fever. In a case-control study, which reported a dose-dependent association between paracetamol use and asthma, a progressively greater risk in those with more severe disease was noted, suggesting an effect on causation and severity of the disease. $^{10}$

The mounting epidemiological evidence, supported by several biologically plausible mechanisms ${ }^{19-28}$ has led to repeated calls ${ }^{2}$ 5-7 13 29-32 for randomised controlled trials to be undertaken to explore the relationship between paracetamol and asthma. This study is the first randomised placebo-controlled trial undertaken to investigate the effect of regular daily paracetamol on asthma severity in adult patients with asthma. It was powered to detect a one doubling dose change in $\mathrm{PC}_{20}$ methacholine bronchial hyper-responsiveness (BHR). Markers of airways inflammation and systemic immunological responses were monitored to provide insight into possible mechanisms of action. The hypothesis was that regular paracetamol use would result in a worsening in BHR and asthma control.

\section{METHODS}

The study design was a double-blind, randomised, placebo-controlled, parallel group trial based in Wellington, New Zealand. The study methods are summarised with additional details provided in the online supplementary appendix.

\section{Participants}

Participants were identified from the Medical Research Institute of New Zealand (MRINZ) asthma register, general practitioner patient databases and the general public through advertising. Inclusion criteria included age between 18 and 65 years, wheeze in the previous 12 months and a doctor's diagnosis of asthma, forced expiratory volume in $1 \mathrm{~s}\left(\mathrm{FEV}_{1}\right) \geq 70 \%$ predicted at screening and baseline and a $\mathrm{PC}_{20} \mathrm{MCh}$ (the provocation concentration of methacholine causing a 20\% reduction in $\mathrm{FEV}_{1}$ ) of between 0.125 and $16 \mathrm{mg} / \mathrm{mL}$ at baseline. Exclusion criteria included regular use of theophylline, ipratropium bromide, tiotropium or leukotriene receptor antagonists in the previous 3 months, alanine aminotransferase (ALT) levels greater than 1.5 times the upper limit of normal at baseline, a history of liver disease or the current use of hepatotoxic drugs, an exacerbation of asthma within the previous 2 months requiring prednisone or nebulised bronchodilator, current or past cigarette smoking $>10$ pack-years, history of sensitivity or allergy to paracetamol or current regular use of paracetamol, use of high-dose aspirin or nonsteroidal anti-inflammatory drugs (NSAIDs), history of alcoholism or current excessive alcohol intake, history of previous intentional overdose of paracetamol, previous suicide attempt or current unstable depression, body mass index $<16 \mathrm{~kg} / \mathrm{m}^{2}$, pregnant or breast-feeding women or women not using adequate contraception and participants unsuitable for BHR challenge testing in accordance with American Thoracic Society (ATS) criteria. $^{33}$

\section{Interventions}

Participants were randomised to receive one of two treatment regimens for 12 weeks. The treatments were paracetamol $1 \mathrm{~g}$, administered as two $500 \mathrm{mg}$ tablets, or placebo administered as two identically appearing tablets, taken twice daily. The paracetamol and placebo tablets were supplied by Aspen Asia Pacific Ltd, Sydney, Australia. All participants were instructed to avoid taking other forms of paracetamol (including over-the-counter remedies containing paracetamol) or NSAIDs for the duration of the study. All participants were provided with a prescription for codeine to use as an analgesic during the study.

\section{Randomisation}

A computer-generated randomisation schedule was generated by the study statistician and was administered by the study pharmacists. It was necessary to randomise the participants prior to their final eligibility screening visit (visit 2) to enable the study pharmacists adequate time to prepare the study medication for dispensing at visit 2 following final determination of eligibility. If a participant failed one of the eligibility criteria at visit 2, the randomised medication was not dispensed and the participant was withdrawn from the study. The randomisation code was not reused.

\section{Blinding}

Study investigators, participants and participant healthcare providers were blinded through provision of medication as identically appearing tablets in bottles, with neither the investigator dispensing the medication nor the participants aware of the allocated treatment.

\section{Design}

The trial involved four study clinic visits and between two and four additional blood tests over 13 weeks (figure 1). A screening visit (visit 1) was held approximately 1 week prior to baseline and consisted of a medical history and brief physical examination, pregnancy test where applicable, bronchodilator reversibility testing, liver function screen and allergy skin prick tests (see online supplementary for details). A diary was used to record morning and evening peak expiratory flow (PEF) values (prior to asthma medication use) for 1 week prior to the second visit. Participants who met initial eligibility criteria were randomised at this stage, prior to final eligibility assessment at visit 2 . 


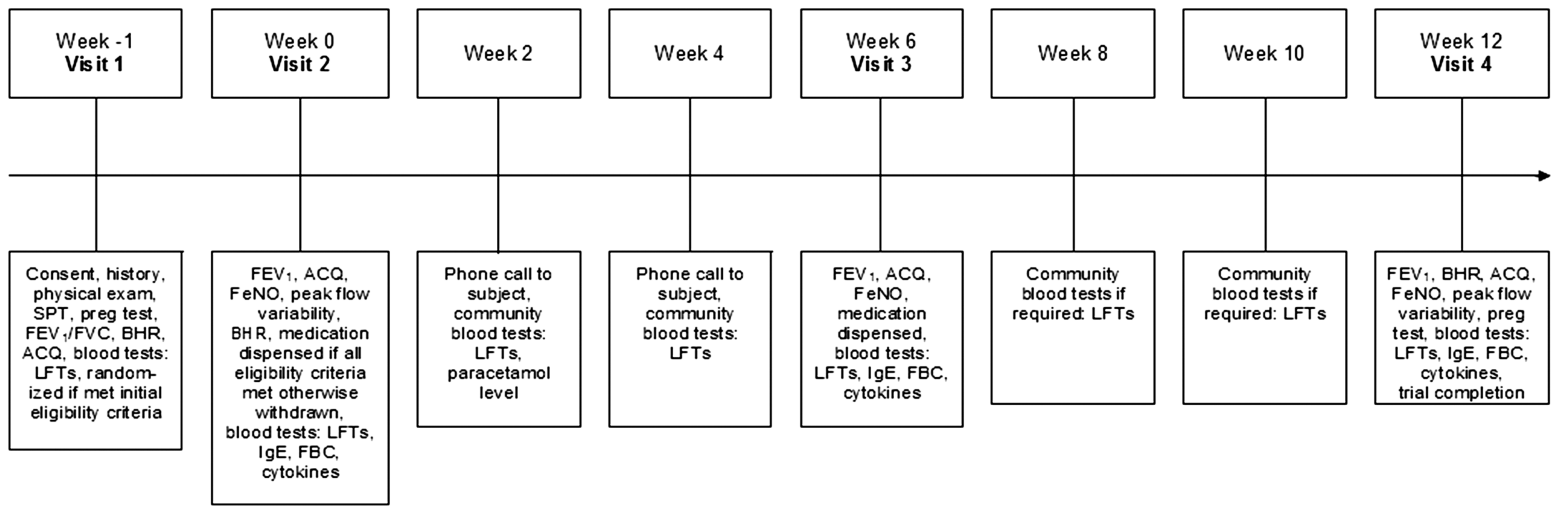

Figure 1 Study design flow chart. SPT, skin prick test; Preg test, pregnancy test; $F E V_{1} / F V C$, forced expiratory volume in 1 s/forced vital capacity; BHR, bronchial hyper-responsiveness testing; ACQ, Asthma Control Questionnaire; LFT, liver function test; FeNO, fractional exhaled nitric oxide; IgE, immunoglobulin E; FBC, full blood count.

At visit 2, designated the baseline visit, the Qoltech asthma control questionnaire (ACQ) ${ }^{34}$ was administered and $\mathrm{PEF}_{\mathrm{var}}(\mathrm{PEF}$ variability measured as the amplitude as a percentage of the mean) calculated. Baseline assessments of $\mathrm{FEV}_{1}$ were undertaken using a micro medical microlab spirometer (Micro Medical, Kent, UK) and fractional exhaled nitric oxide (FeNO) was assessed using a NiOX Flex chemiluminescence analyser (Aerocrine AB, Stockholm, Sweden). Methacholine (Methapharm, Ontario, Canada) challenge testing was undertaken via the 2 min tidal breathing dosing protocol recommended by the ATS, ${ }^{33}$ as outlined in the online supplementary. Participants who met all the eligibility criteria were then dispensed a 6-week supply of randomised medication, a medication diary to record administered doses and a prescription for codeine phosphate for emergency pain relief during the trial period. These participants then underwent blood tests including full blood count (eosinophils), total serum immunoglobulin E ( $\mathrm{IgE}$ ) and serum cytokine levels (interferon (IFN)- $\gamma$, interleukin (IL)-4, IL-5, IL-13; see online supplementary for details).

At visits 3 and 4, 6 and 12 weeks after baseline, $\mathrm{FEV}_{1}$, ACQ, FeNO and blood tests were repeated and medication compliance checked via pill count and medication diary check (see online supplementary for details). At the third visit, participants were given a further 6-week supply of study medication, a second medication diary and a diary to record morning and evening PEF values in the final intervention week. At the fourth and final visit, BHR testing was repeated. Liver function tests were monitored throughout the study (see online supplementary for details).

\section{Outcomes}

The primary outcome variable was $\mathrm{PC}_{20} \mathrm{MCh}$ at 12 weeks, adjusted for baseline. This direct measure of BHR was chosen as an objective well-standardised physiological measure of asthma severity, recommended for monitoring the effects of therapy which may modify asthma severity. ${ }^{33}{ }^{35}$ Secondary outcome measures were $\mathrm{FEV}_{1}, \mathrm{FEV}_{1} \%$ predicted, ACQ score and FeNO at 6 and 12 weeks, and the mean morning peak flow, $\mathrm{PEF}_{\mathrm{var}}$ and exacerbations of asthma (requiring a doctor's visit and need for prednisone or nebulised bronchodilator) at 12 weeks. Blood eosinophil, serum IgE and serum cytokine (IFN- $\gamma$, IL-4, IL-5 and IL-13) levels were measured at 6 and 12 weeks.

\section{Statistical methods}

The primary analysis method was analysis of covariance (ANCOVA). The logarithm base two $\mathrm{PC}_{20}$ for methacholine at 12 weeks was the primary response variable, with the baseline logarithm base two $\mathrm{PC}_{20}$ as a covariate and a categorical variable for the paracetamol group. The difference in logarithm base two $\mathrm{PC}_{20}$ was the doubling dose difference between the two randomised groups. Secondary outcome variables, including $\mathrm{FEV}_{1}, \mathrm{FEV}_{1} \%$ predicted, ACQ score, FeNO, mean morning peak flow and $\mathrm{PEF}_{\mathrm{var}}$ were also analysed by ANCOVA. The distribution of FeNO, serum IgE and eosinophil count was skewed and normality assumptions for these variables were best met on the natural logarithm scale.

The proportion of participants with at least one asthma exacerbation was compared as an absolute risk difference, with an appropriate CI, because in the event there were no asthma exacerbations in one of the randomised groups, and as a result a relative risk could not be calculated. Simple t tests were used to compare mean values for ALT by randomised group. FeNO, eosinophil count and IgE were logarithm transformed because of skewed distributions, and the difference in logarithms was compared by a $t$ test. For those three variables with a logarithm transformation, the exponent of the difference in logarithms is interpreted as the ratio of mean values.

The analysis was by intention to treat randomised participants who passed the final eligibility screening and as a result received randomised treatment. Randomised participants who failed the final eligibility screen did not 
receive randomised treatment or undergo any outcome assessments. For each individual analysis, a two-sided $\mathrm{p}$ value of 0.05 was used, with $95 \%$ CIs for each estimate. We have not adjusted for multiple statistical testing.

\section{Sample size}

A sample size of 60 in each group has $80 \%$ power at the $5 \%$ level of significance to detect a difference of one doubling dose in $\mathrm{PC}_{20} \mathrm{MCh}$ between the groups, based on an $\mathrm{SD}$ of $1.9{ }^{36}$ To allow for the possibility of up to $10 \%$ of study participants withdrawing early from the study, a recruitment target of 66 participants was set for each group.

\section{RESULTS}

Recruitment started in June 2009 and ended in September 2011. The planned study period of 2 years was extended by 3 months due to difficulties in recruitment. Figure 2 shows the flow of participants. There were 724 patients assessed for eligibility by phone screening and/ or at visit 1; of these, 338 failed to meet the inclusion criteria and 205 declined to participate (see online supplementary). There were 181 participants randomised prior to visit 2 based on initial eligibility at visit 1; 91 to the paracetamol group and 92 to the placebo group. Of the total number of participants allocated to the paracetamol group 53/91 were withdrawn, and 34/92 were withdrawn from the placebo group at visit 2 as they either did not meet the inclusion/exclusion criteria $\left(\mathrm{PC}_{20}>16 \mathrm{mg} / \mathrm{mL}\right.$, $\mathrm{n}=68 ; \mathrm{PC}_{20}<0.125 \mathrm{mg} / \mathrm{mL}, \mathrm{n}=3 ; \mathrm{FEV}_{1}<70 \%$ predicted, $\mathrm{n}=6$; unable to perform spirometry, $\mathrm{n}=1$ ) or were lost to follow-up or withdrew consent $(n=9)$. Study medication was not dispensed to the participants who were withdrawn at visit 2 (see online supplementary).

Medication was dispensed to 94 participants who started the intervention phase following visit 2: 36 randomised to paracetamol and 58 to placebo. The characteristics of participants are shown in table 1 . The mean age of participants was 40 years and there were 59 female participants. Approximately $30 \%$ of study participants were prescribed inhaled corticosteroids and $18 \%$ prescribed long-acting $\beta$ agonist drugs. Around $90 \%$ of participants had positive skin prick tests to either cat, mixed grass or house dust mite. Participants had mild-to-moderate asthma, with a baseline ACQ score of 0.86 (SD 0.59). The baseline mean $\mathrm{FeNO}$ was $48.9 \mathrm{ppb}$ (SD 41.3) and the mean $\mathrm{FEV}_{1}$ was $94 \%$ of predicted (SD 12.0). The baseline mean $\mathrm{PC}_{20}$ was $4.29 \mathrm{mg} / \mathrm{mL}$ (SD 4.54).

There were 85/94 participants who completed the study. Five participants were withdrawn from the paracetamol group; two withdrew at the participant's own discretion, one was excluded due to a raised ALT (119 IU/L), one was lost to follow-up and one was excluded due to intercurrent illness. Four participants were withdrawn from the placebo group; two were excluded due to a raised ALT (207 and $227 \mathrm{IU} / \mathrm{L}$, respectively), one withdrew at the participant's own discretion and one was lost to follow-up.

\section{Primary outcome variable}

At 12 weeks the mean (SD) logarithm base two $\mathrm{PC}_{20}$ was 1.07 (2.36) in the control group ( $\mathrm{N}=54)$ and $0.62(2.09)$
Figure 2 CONSORT participant flow diagram.

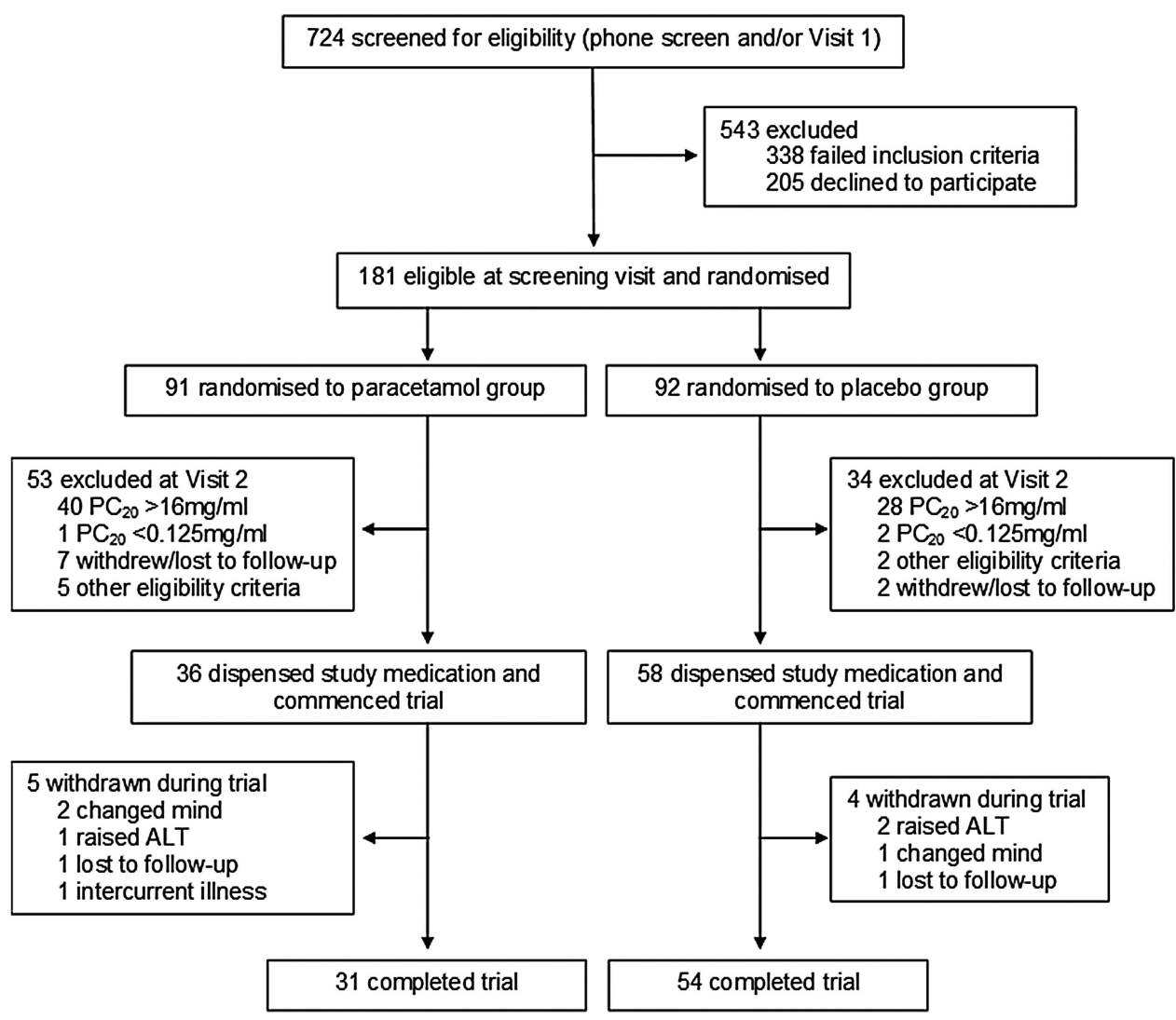


Table 1 Characteristics of participants who received randomised treatment

\begin{tabular}{|c|c|c|}
\hline & Paracetamol group & Placebo group \\
\hline \multicolumn{3}{|l|}{ Demographic } \\
\hline Male sex, $\mathrm{N}(\%)$ & $15(41.7)$ & $20(34.5)$ \\
\hline Weight, $\mathrm{kg} \pm \mathrm{SD}$ & $75.1 \pm 16.7$ & $77.4 \pm 17.8$ \\
\hline Height, $m \pm S D$ & $1.7 \pm 0.1$ & $1.69 \pm 0.11$ \\
\hline ICS, N (\%) & $9(25 \%)$ & $20(34 \%)$ \\
\hline SABA, N (\%) & $33(92 \%)$ & 55 (95\%) \\
\hline LABA, N (\%) & $9(25 \%)$ & $8(14 \%)$ \\
\hline \multicolumn{3}{|l|}{ Defining study population } \\
\hline $\mathrm{FEV}_{1}, \mathrm{~L} \pm \mathrm{SD}$ & $3.09 \pm 0.78$ & $3.12 \pm 0.87$ \\
\hline SPT mixed grass, $\mathrm{N}(\%+\mathrm{ve})$ & $25(69.4)$ & $38(66.7)$ \\
\hline SPT at least one positive, no $(\%+v e)$ & $33(91.7)$ & $55(96.5)$ \\
\hline \multicolumn{3}{|l|}{ Clinical and physiological measurements } \\
\hline $\mathrm{PC}_{20} \mathrm{MCh}, \mathrm{mg} / \mathrm{mL} \pm \mathrm{SD}$ & $4.14 \pm 4.42$ & $4.39 \pm 4.66$ \\
\hline Mean morning peak flow, L/min $\pm S D$ & $424.0 \pm 83.8$ & $419.5 \pm 92.3$ \\
\hline $\mathrm{PEF}_{\mathrm{var}}, \%, \pm \mathrm{SD}$ & $19.0 \pm 9.3$ & $22.2 \pm 10.5$ \\
\hline $\mathrm{ACQ}$ score $\pm \mathrm{SD}$ & $0.93 \pm 0.63$ & $0.82 \pm 0.56$ \\
\hline \multicolumn{3}{|l|}{ Inflammation and immunology } \\
\hline FeNO, ppb $\pm S D$ & $44.9 \pm 39.2$ & $51.3 \pm 42.6$ \\
\hline Eosinophils, $\times 10^{9} / \mathrm{L}, \pm \mathrm{SD}$ & $0.26 \pm 0.12$ & $0.32 \pm 0.17$ \\
\hline $\operatorname{lgE}, \mathrm{kU} / \mathrm{L}, \pm \mathrm{SD}$ & $518.4 \pm 705.7$ & $480.4 \pm 914.0$ \\
\hline
\end{tabular}

in the paracetamol group $(\mathrm{N}=31)$. After controlling for baseline $\mathrm{PC}_{20}$, the difference (expressed as a doubling dose difference, paracetamol minus placebo) was not statistically significant: $-0.48(95 \%$ CI -1.28 to 0.32$)$, $\mathrm{p}=0.24$ (table 2).

\section{Secondary outcome variables}

There were no statistically significant differences in $\mathrm{FEV}_{1}, \mathrm{FEV}_{1} \%$ predicted, ACQ score, mean morning peak flow or $\mathrm{PEF}_{\mathrm{var}}$ between the control and paracetamol groups at week 12 (table 2), or in $\mathrm{FEV}_{1}$ or ACQ score at week 6 (see online supplementary). There were three asthma exacerbations in the placebo group and none in the paracetamol group, an absolute difference of $5.6 \%(95 \%$ CI $-0.5 \%$ to $11.7 \%)$. There was $93.2 \%$ compliance in the control group and $90.8 \%$ compliance in the paracetamol group when assessed by pill count and medication diaries, a difference of $2.4 \%$ (95\% CI $-1.0 \%$ to $5.8 \%$ ). Serum paracetamol levels (greater than the $30 \mu \mathrm{mol} / \mathrm{L}$ threshold) were detectable in between $31.3 \%$ to $38.7 \%$ of participants in the paracetamol group and were undetectable in all participants in the placebo group between weeks 2 and 12 of the study.
There were no statistically significant differences observed in $\log$ FeNO at week 6 (see online supplementary), at week 12, in $\log$ eosinophil or $\log$ IgE levels between the two groups at week 12 (table 3). Only a proportion of participants had measurable levels of IFN- $\gamma$, IL-4, IL-5 and IL-13 at baseline or at other times throughout the trial, precluding meaningful analysis (see online supplementary). ALT levels were significantly higher in the paracetamol group, with a mean ALT of 25.4 (SD 9.7) and 19.0 (SD 6.0) in the paracetamol and placebo groups, respectively, at visit 4 , difference 6.3 $(95 \%$ CI 2.9 to $9.7, \mathrm{p}<0.001)$.

\section{DISCUSSION}

This double-blind, randomised, placebo-controlled, parallel group study found no statistically significant increase in BHR with 12 weeks of paracetamol treatment. However, the results did not rule out a clinically significant effect, with the $95 \%$ CI containing the prespecified difference of one doubling dose reduction in $\mathrm{PC}_{20}$. There were no significant differences observed in any of the prespecified secondary outcome variables of asthma control, inflammatory or immunological markers. 
Table 2 Effect of paracetamol use on BHR, lung function and asthma control

\begin{tabular}{|c|c|c|c|c|c|}
\hline & \multicolumn{2}{|l|}{ Baseline } & \multicolumn{2}{|l|}{ Week 12} & \multirow[b]{2}{*}{$\begin{array}{l}\text { Difference } \\
\text { (adjusted for baseline) }\end{array}$} \\
\hline & $\begin{array}{l}\text { Paracetamol } \\
\mathrm{N}=36\end{array}$ & $\begin{array}{l}\text { Placebo } \\
\mathrm{N}=58\end{array}$ & $\begin{array}{l}\text { Paracetamol } \\
\mathrm{N}=31\end{array}$ & $\begin{array}{l}\text { Placebo } \\
N=54\end{array}$ & \\
\hline $\log 2 \mathrm{PC}_{20}(\mathrm{mg} / \mathrm{mL})$ & $1.30(1.50)$ & $1.09(1.96)$ & $0.62(2.09)$ & $1.07(2.36)$ & $-0.48(-1.28$ to 0.32$) p=0.24^{*}$ \\
\hline $\mathrm{FEV}_{1}(\mathrm{~L})$ & $3.06(0.73)$ & $3.05(0.83)$ & $3.01(0.74)$ & $3.07(0.86)$ & $-0.07(-0.15$ to 0.01$) p=0.08$ \\
\hline ACQ score & $0.81(0.47)$ & 0.93 (0.59) & $0.88(0.56)$ & $1.03(0.71)$ & $-0.04(-0.27$ to 0.18$) p=0.71$ \\
\hline Mean morning peak flow (L/min) & $424.0(83.8)$ & $419.5(92.3)$ & $417.1(82.3)$ & $417.5(85.9)$ & $-8.6(-26.7$ to 9.5$) p=0.35$ \\
\hline $\operatorname{PEF}_{\mathrm{var}}(\%)$ & $19.0(9.3)$ & $22.2(10.5)$ & $20.4(10.3)$ & $21.7(11.7)$ & $0.21(-4.3$ to 4.8$) p=0.93$ \\
\hline
\end{tabular}

Numbers are mean (SD).

${ }^{*}$ Difference in doubling doses.

$\mathrm{ACQ}$, Asthma Control Questionnaire; BHR, bronchial hyper-responsiveness testing; $\mathrm{FEV}_{1}$, forced expiratory volume in one second; $\mathrm{PC}_{20}$

provocation concentration of methacholine causing a $20 \%$ fall in $\mathrm{FEV}_{1} ; \mathrm{PEF}_{\mathrm{var}}$, PEF variability (measured as amplitude as a percentage of the mean).

This is the first reported randomised placebocontrolled trial of the effects of the use of daily paracetamol in stable adult asthma. The only other published randomised controlled trial of paracetamol and asthma was the Boston University Fever Study. ${ }^{18}$ Children randomised to the ibuprofen group had a reduced risk of having an outpatient visit for asthma during the 4-week study period (OR $0.56,95 \%$ CI 0.34 to 0.95 ) compared with children in the paracetamol group. Because the study did not include a placebo treatment, it was not possible to determine whether the observed difference in morbidity according to treatment group was attributable to an increased risk with paracetamol or a decreased risk with ibuprofen.

There are several methodological issues relevant to the interpretation of our study findings. First, as enshrined in the Declaration of Helsinki ${ }^{37}$ there is a requirement to study the least vulnerable populations wherever applicable. Most, but not all, of the putative adverse effects of paracetamol on asthma have been shown in observational studies of children and suggest that paracetamol may increase the risk of developing asthma. ${ }^{12}$ However, as there is some data to suggest that regular paracetamol use may lead to a deterioration in asthma control in adults, ${ }^{1}{ }^{10}$ we opted to first examine the effects of paracetamol in adults with stable asthma.

Second, this trial was powered to determine whether there was an effect on BHR of at least one doubling dose reduction in $\mathrm{PC}_{20} \mathrm{MCh}$. Our ability to achieve the designated sample size completing the study was affected by several factors. First, despite a rigorous recruitment campaign during which over 700 patients were screened, due to the inclusion and exclusion criteria employed to ensure participant safety, only 94 screened participants were dispensed randomised medication. Second, variability in $\mathrm{PC}_{20}$ from baseline to week 12 was larger than anticipated, with a pooled SD of 2.27 doubling doses compared with that used in the sample size calculation based on an SD of 1.9, derived from previous studies. ${ }^{36}$ Another factor that affected the study power was the requirement to randomise participants prior to their final screening visit in order to allow the pharmacy adequate time for dispensing at visit 2, following final determination of eligibility. If the participant failed this final eligibility, the randomised medication was not dispensed, the participant was withdrawn from the study and the randomisation code was not reused. By chance, this resulted in a disparity between the proportion of participants receiving active and placebo study medication. The power was reduced further due to the withdrawal of $10 \%$ of participants after randomised treatment was dispensed. As there is an uncertain association between observed variables and missing BHR data in these participants, it was not possible to perform a robust imputation.

Compliance was high when measured via pill count, and although less than half of participants in the paracetamol group had measurable levels of paracetamol in the blood at the times tested throughout the study, this is likely to be due to the laboratory cut-off for a

Table 3 Effect of paracetamol use on FeNO, blood eosinophil count and serum IgE

\begin{tabular}{|c|c|c|c|c|c|}
\hline & \multicolumn{2}{|l|}{ Baseline } & \multicolumn{2}{|l|}{ Week 12} & \multirow[b]{2}{*}{ Difference (adjusted for baseline) } \\
\hline & $\begin{array}{l}\text { Paracetamol } \\
\mathrm{N}=36\end{array}$ & $\begin{array}{l}\text { Placebo } \\
\mathrm{N}=58\end{array}$ & $\begin{array}{l}\text { Paracetamol } \\
\mathrm{N}=31\end{array}$ & $\begin{array}{l}\text { Placebo } \\
N=54\end{array}$ & \\
\hline Log FeNO (ppb) & $3.53(0.71)$ & $3.66(0.78)$ & $3.69(0.70)$ & $3.65(0.76)$ & $0.09(-0.097$ to 0.27$) p=0.36$ \\
\hline Log eosinophils $\left(\times 10^{9} / \mathrm{L}\right)$ & $-1.41(0.47)$ & $-1.27(0.53)$ & $-1.33(0.54)$ & $-1.32(0.58)$ & $-0.056(-0.25$ to 0.14$) p=0.57$ \\
\hline $\log \lg E(k U / L)$ & $5.28(1.52)$ & $5.29(1.30)$ & $5.02(1.56)$ & $5.20(1.37)$ & 0.098 (0.009 to 0.21$) p=0.073$ \\
\hline
\end{tabular}

FeNO, fractional exhaled nitric oxide; IgE, immunoglobulin $\mathrm{E}$. 
detectable paracetamol level $(30 \mu \mathrm{mol} / \mathrm{L})$. Following a $1 \mathrm{~g}$ dose, participant blood levels may fall below this laboratory cut-off level in as little as $3 \mathrm{~h}$ (given a paracetamol half-life of $2 \mathrm{~h}$ and a peak plasma concentration $1 \mathrm{~h}$ after administration of $\left.80 \mu \mathrm{mol} / \mathrm{L}^{38}\right)$. The use of this laboratory cut-off for paracetamol levels meant that it was not possible to investigate medication compliance through this method.

Our 12-week dosing period was chosen based on evidence that regular, long-term use of paracetamol is associated with an increased risk of asthma in adults ${ }^{9-11} 1617$ and that chronic ingestion of therapeutic doses can reduce serum antioxidant capacity in as little as 2 weeks. $^{39}$ We had originally intended to use the maximum daily dose of $4 \mathrm{~g}$ paracetamol, however, chose to administer half this dose due to concerns of liver toxicity. These concerns were based on a previous clinical trial of paracetamol in which the incidence of ALT elevations more than three times the upper limit of normal in healthy participants taking $4 \mathrm{~g}$ /day for 14 days was $31-44 \% .{ }^{40}$ Our results showed no clinically significant liver function derangement with paracetamol administered at a dose of $2 \mathrm{~g}$ /day for 12 weeks.

While the study did not demonstrate a statistically significant effect of paracetamol on BHR to MCh, the results do not rule out a clinically significant effect, with the upper $95 \%$ CI of a 1.28 doubling dose worsening in BHR containing the prespecified difference of one doubling dose. Furthermore, our point estimate of a reduction in $\mathrm{PC}_{20}$ of 0.48 of a doubling dose could potentially be of major public health significance. As proposed by Mitchell, ${ }^{41}$ a small shift to the left of the BHR curve in a population could lead to a relatively large increase in the prevalence of severe asthma. Relevant to the interpretation of our findings it has recently been calculated that a one half doubling dose increase in BHR increases the prevalence of moderate and severe BHR by about $30 \% .{ }^{42}$ Likewise, although the $9 \%$ increase in FeNO with paracetamol was not statistically significant, a change of this magnitude is considered clinically significant. ${ }^{43}$ For $\mathrm{FEV}_{1}$, the point estimate was consistent with a lower value in the paracetamol group, however, the difference was of uncertain clinical significance and was associated with wide CIs.

No significant effect was seen on serum IgE or peripheral blood eosinophil levels. It was not possible to undertake any meaningful analysis of the cytokine measurements due to the low numbers of participants with detectable levels, and as a result we were unable to determine whether paracetamol influenced the Th1/Th2 balance. Another less recognised potential mechanism of action, which was not directly assessed in this study, relates to neurogenic inflammation of the airways through the stimulation of the transient receptor potential ankyrin-1 cation channel by $N$-acetyl- $p$-benzoquinoneimine, the metabolite of paracetamol. ${ }^{26}$ This pathway, which is activated following therapeutic doses of paracetamol, mediates a non-eosinophilic inflammatory response and has been implicated in the pathogenesis or provocation of asthma by isocyanates, aldehydes, cigarette smoke and chlorine. ${ }^{44} 45$

Our findings provide information on which the design of further studies could be based. A trial of similar design, utilising the same duration and dose of paracetamol and with BHR testing to $\mathrm{MCh}$ as the primary outcome variable, based on the SD derived from this study, would require a sample size of approximately 650 to attain adequate power to detect a difference of 0.5 doubling doses. Alternatively, a study of short-term use of paracetamol at higher doses could be undertaken, to more closely replicate the common use of paracetamol for relief of fever or pain in self-limited illnesses. Based on our findings, a sample size of 140 would be adequate to determine a 0.5 doubling dose difference in MCh $\mathrm{BHR}$, and a $10 \%$ increase in FeNO, in a short-term study of crossover design. Important issues with the design of such a study are the duration of the treatment periods and the crossover period. It would be important if possible to include a placebo rather than ibuprofen arm, as NSAIDs may have the potential to both cause NSAID-induced bronchospasm, as well as reducing asthma severity with long-term use. ${ }^{29}$

Finally, our study investigated the effect of paracetamol on asthma severity and not whether paracetamol has a role in the pathogenesis of asthma. Testing this hypothesis would require clinical trials of the effect of paracetamol use in pregnancy on the development of asthma in childhood and the effect of paracetamol use in infants and older children and subsequent asthma risk. Such studies would raise ethical and practical issues regarding consent and the use of placebo for the management of pain or fever during pregnancy and in young children. However, given the common usage of paracetamol in all age groups including pregnancy and the global burden of asthma, we propose that randomised controlled trials are required to determine the effect of paracetamol use on the development of asthma in infancy and early childhood.

In conclusion, this study has shown no significant effect of 12 weeks of treatment with paracetamol at half the maximum therapeutic daily dose on BHR and asthma control in adults with well-controlled asthma. While this outcome provides some reassurance that regular paracetamol use has no marked deleterious effect in adult asthma, further adequately powered studies are needed before the safety of paracetamol for patients with asthma is assured. Furthermore, the study findings do not preclude an effect of paracetamol on the development of asthma in infancy, childhood or adult life.

Contributors SJI and RB contributed to study planning, study conduct, data analysis and manuscript preparation. KP contributed to study planning, study conduct and manuscript preparation. MW, SJ and MP contributed to study conduct. MW contributed to randomisation, statistical analysis and preparation of manuscript. RS contributed to blood analysis and preparation of manuscript. JC contributed to study planning and manuscript preparation. JT and PS were safety investigators. 
Funding Funding for the study was through research grants from the Health Research Council of New Zealand, the Wellington Medical Research Foundation, the Asthma and Respiratory Foundation of New Zealand and the University of Otago.

Competing interests RB has been a member of the GlaxoSmithKline (NZ) Advisory Board, and received research grants, payment for lectures or support to attend meetings from GlaxoSmithKline, a manufacturer of paracetamol. SJI is a Health Research Council Clinical Research Training Fellow.

Ethics approval The study was approved by the Central Regional Ethics Committee (CEN/08/12/070) and all participants gave written informed consent. The trial was registered on the Australian New Zealand Clinical Trials Registry (ACTRN12609000551291)

Provenance and peer review Not commissioned; externally peer reviewed.

Data sharing statement No additional data are available.

Open Access This is an Open Access article distributed in accordance with the Creative Commons Attribution Non Commercial (CC BY-NC 3.0) license, which permits others to distribute, remix, adapt, build upon this work noncommercially, and license their derivative works on different terms, provided the original work is properly cited and the use is non-commercial. See: http:// creativecommons.org/licenses/by-nc/3.0/

\section{REFERENCES}

1. Farquhar $\mathrm{H}$, Stewart $\mathrm{A}$, Mitchell $\mathrm{E}$, et al. The role of paracetamol in the pathogenesis of asthma. Clin Exp Allergy 2010;40:32-41.

2. McBride JT. The Association of acetaminophen and asthma prevalence and severity. Pediatrics 2011;128:1181-5.

3. Eyers S, Weatherall M, Jefferies S, et al. Paracetamol in pregnancy and the risk of wheezing in offspring: a systematic review and meta-analysis. Clin Exp Allergy 2011;41:482-9.

4. Shaheen SO, Newson RB, Sherriff $A$, et al. Paracetamol use in pregnancy and wheezing in early childhood. Thorax 2002;57:958-63.

5. Amberbir A, Medhin G, Alem A, et al. The role of acetaminophen and geohelminth infection on the incidence of wheeze and eczema: a longitudinal birth-cohort study. Am J Respir Crit Care Med 2010;183:165-70.

6. Beasley R, Clayton T, Crane J, et al. Association between paracetamol use in infancy and childhood, and risk of asthma, rhinoconjunctivitis, and eczema in children aged 6-7 years: analysis from Phase Three of the ISAAC programme. Lancet 2008;372:1039-48.

7. Beasley RW, Clayton TO, Crane J, et al. Acetaminophen use and risk of asthma, rhinoconjunctivitis and eczema in adolescents: ISAAC Phase Three. Am J Respir Crit Care Med 2011;183:171-8.

8. Davey G, Berhane Y, Duncan P, et al. Use of acetaminophen and the risk of self-reported allergic symptoms and skin sensitization in Butajira, Ethiopia. J Allergy Clin Immunol 2005;116:863-8.

9. McKeever TM, Lewis SA, Smit HA et al. The association of acetaminophen, aspirin, and ibuprofen with respiratory disease and lung function. Am J Respir Crit Care Med 2005;171:966-71.

10. Shaheen SO, Sterne JA, Songhurst CE, et al. Frequent paracetamo use and asthma in adults. Thorax 2000;55:266-70.

11. Shaheen S, Potts J, Gnatiuc L, et al. The relation between paracetamol use and asthma: a GA2LEN European case-control study. Eur Respir J 2008;32:1231-6.

12. Schnabel E, Heinrich J. Respiratory tract infections and not paracetamol medication during infancy are associated with asthma development in childhood. J Allergy Clin Immunol 2010;126:1071-3.

13. Tapiainen $T$, Dunder $T$, Mottonen $M$, et al Adolescents with asthma or atopic eczema have more febrile days in early childhood: a possible explanation for the connection between paracetamol and asthma? J Allergy Clin Immunol 2010;125:751-2.

14. Lowe AJ, Carlin JB, Bennett CM, et al. Paracetamol use in early life and asthma: prospective birth cohort study. BMJ 2010;341:c4616.

15. Kreiner-Møller $\mathrm{E}$, Sevelsted A, Vissing $\mathrm{NH}$, et al. Infant acetaminophen use associates with early asthmatic symptoms independently of respiratory tract infections: The Copenhagen Prospective Study on Asthma in Childhood 2000 (COPSAC $_{2000}$ ) cohort. J Allergy Clin Immunol 2012;130:1434-6.

16. Barr RG, Wentowski CC, Curhan GC, et al. Prospective study of acetaminophen use and newly diagnosed asthma among women. Am J Respir Crit Care Med 2004;169:836-41.
17. Thomsen SF, Kyvik KO, Skadhauge L, et al. Intake of paracetamol and risk of asthma in adults. J Asthma 2008;45:675-6.

18. Lesko SM, Louik C, Vezina RM, et al. Asthma morbidity after the short-term use of ibuprofen in children. Pediatrics 2002;109:E20.

19. Rahman I, MacNee W. Oxidative stress and regulation of glutathione in lung inflammation. Eur Respir J 2000;16:534-54.

20. Chen TS, Richie JP Jr, Lang CA. Life span profiles of glutathione and acetaminophen detoxification. Drug Metab Dispos 1990;18:882-7.

21. Dimova $S$, Hoet $P$, Dinsdale $D$, et al. Acetaminophen decreases intracellular glutathione levels and modulates cytokine production in human alveolar macrophages and type II pneumocytes in vitro. Int $J$ Biochem Cell Biol 2005;37:1727-37.

22. Kozer E, Evans S, Barr J, et al. Glutathione, glutathione-dependent enzymes and antioxidant status in erythrocytes from children treated with high-dose paracetamol. Br J Clin Pharmacol 2003;55:234-40.

23. Micheli L, Cerretani D, Fiaschi Al, et al. Effect of acetaminophen on glutathione levels in rat testis and lung. Environ Health Perspect 1994;102(Suppl 9):63-4.

24. Eneli I, Sadri K, Camargo C Jr, et al. Acetaminophen and the risk of asthma: the epidemiologic and pathophysiologic evidence. Chest 2005;127:604-12.

25. Lenney $\mathrm{W}$, Fryer AA. The genetics of asthma: are the glutathione S-transferases serious players? Clin Exp Allergy 2007;37:1124-6.

26. Nassini R, Materazzi S, Andre E, et al. Acetaminophen, via its reactive metabolite $\mathrm{N}$-acetyl-p-benzo-quinoneimine and transient receptor potential ankyrin-1 stimulation, causes neurogenic inflammation in the airways and other tissues in rodents. FASEB J 2010;24:4904-16.

27. Peterson JD, Herzenberg LA, Vasquez K, et al. Glutathione levels in antigen-presenting cells modulate Th1 versus Th2 response patterns. Proc Natl Acad Sci USA 1998;95:3071-6.

28. Prymula R, Siegrist CA, Chlibek R, et al. Effect of prophylactic paracetamol administration at time of vaccination on febrile reactions and antibody responses in children: two open-label, randomised controlled trials. Lancet 2009;374:1339-50.

29. Barr RG. Does paracetamol cause asthma in children? Time to remove the guesswork. Lancet 2008;372:1011-12.

30. Farquhar $\mathrm{H}$, Crane J, Mitchell EA, et al. The acetaminophen and asthma hypothesis 10 years on: a case to answer. J Allergy Clin Immunol 2009;124:649-51.

31. Johnson CC, Ownby DR. Have the efforts to prevent aspirin-related Reye's syndrome fuelled an increase in asthma? Clin Exp Allergy 2011;41:296-8.

32. Holgate ST. The acetaminophen enigma in asthma. Am J Respir Crit Care Med 2011:183:147-8.

33. American Thoracic Society. Guidelines for methacholine and exercise challenge testing 1999. Am J Respir Crit Care Med 2000;161:309-29.

34. Juniper EF, O'Byrne PM, Guyatt GH, et al. Development and validation of a questionnaire to measure asthma control. Eur Respir $J$ 1999;14:902-7.

35. Reddel HK, Taylor DR, Bateman ED, et al. An official American Thoracic Society/European Respiratory Society statement: asthma control and exacerbations. Standardizing endpoints for clinical asthma trials and clinical practice. Am J Respir Crit Care Med 2009;180:59-99.

36. Chinn S, Schouten JP. Reproducibility of non-specific bronchial challenge in adults: implications for design, analysis and interpretation of clinical and epidemiological studies. Thorax 2005;60:395-400.

37. World Medical Association: declaration of Helsinki ethical principles for medical research involving human subjects. JAMA 2000;284:3043-5.

38. Gibb IA, Anderson BJ. Paracetamol (acetaminophen) pharmacodynamics: interpreting the plasma concentration. Arch Dis Child 2008;93:241-7.

39. Nuttall SL, Khan JN, Thorpe GH, et al. The impact of therapeutic doses of paracetamol on serum total antioxidant capacity. J Clin Pharm Ther 2003;28:289-94.

40. Watkins PB, Kaplowitz N, Slattery JT, et al. Aminotransferase elevations in healthy adults receiving 4 grams of acetaminophen daily-a randomized controlled trial. JAMA 2006;296:87-93.

41. Mitchell EA. Is current treatment increasing asthma mortality and morbidity? Thorax 1989;44:81-4.

42. Weatherall M, Fingleton J, Eyers S, et al. A half doubling dose change in bronchial hyperresponsiveness in a population represents an important difference. Trans Resp Med 2013;1:4.

43. Lim KG, Mottram C. The use of fraction of exhaled nitric oxide in pulmonary practice. Chest 2008;133:1232-42.

44. Bautista DM, Jordt SE, Nikai T, et al. TRPA1 mediates the inflammatory actions of environmental irritants and proalgesic agents. Cell 2006;124:1269-82.

45. Caceres Al, Brackmann M, Elia MD, et al. A sensory neuronal ion channel essential for airway inflammation and hyperreactivity in asthma. Proc Natl Acad Sci USA 2009;106:9099-104. 